\section{Translation Techniques and Translation Quality of Indonesian Subtitles of Coco Movie: A Comparative of Two Subtitlers}

1. Annisa Risma Khairani Lubis

2 Muhizar Muchtar

3 Umar Mono

123 Universitas Sumatera Utara, Indonesia

\begin{abstract}
The objectives of the research are to identify the types of translation technique, to evaluate the translation quality and to find out the effect of translation techniques on the translation quality used by Pein Akatsuki and Deni Aurora in Indonesian subtitles of Coco movie. This research applies descriptive qualitative method to assess data with documents and informants as source of data. The result shows that there are 16 types of translation techniques used by Pein Akatsuki and Deni Aurora in translating Indonesian subtitles. For both subtitlers, literal translation and borrowing create high level of accuracy, acceptability, and readability. Modulation and the other techniques are showed in high and medium levels of accurate translation, but they result in high levels of acceptability and readability. Based on the findings, the translation techniques applied by the subtitlers contribute positively to the quality of Indonesian subtitles in terms of accuracy, acceptability, and readability.
\end{abstract}

\section{Keywords}

subtitle

translation technique

translation quality

\section{Ethical Lingua}

Vol. 7, No. 2, 2020

ISSN 2355-3448 (Print)

ISSN 2540-9190 (Online)

Corresponding Email Annisa Risma Khairani Lubis annisalubiss@gmail.com

Article's History

Submitted 28 June 2020

Revised 25 September 2020

Revised 28 September 2020

Accepted 28 September 2020

\section{DOI}

10.30605/25409190.203

Copyright (๑) 2020

The Author(s)

This article is licensed under CC BY-NC-SA 4.0 License 


\section{Translation Techniques and Translation Quality of Indonesian Subtitles of Coco Movie: A Comparative of Two Subtitlers}

The presence of films nowadays in our society is very big. Film has beneficial effects on learners' language performance in listening and speaking, because the dialogues work together with visual images, sound tracks and music (Chang, 2012). Foreign films/movies currently dominate the movie industry in Indonesia. For example, Hollywood films/movies from the United States are more in demand and consumed than Indonesian films. In general, Hollywood films always use English. However, not all Indonesian people master English well. It can be an obstacle for them in understanding the film because of the difference of language used. Therefore, it is necessary to have a language transfer or better known as "translation", so that the film can be enjoyed and understood properly by the audience.

One type of Audiovisual Translation (AVT) is subtitling which represents the language transfer method used in translating types of mass audio-visual communication such as film and television by involving a mode shift from spoken to written form. Subtitling has some constraints and limitations. The subtitlers must consider time and space limitations so that the translated text can appear in accordance with the image or display on the screen and the translation displayed both orally and in text. High-level constraints of subtitling involve in transferring the text in the source language to the target language (Kinasih, 2016). There are differences in language systems at the level of words, linguistics and grammar because each language has a different structure, grammar and vocabulary. In translating films, there are several factors that must be considered such as historical circumstances, traditions, techniques used for both the source and the target audience (Aveline, 2015).

A good translation in the movie is determined by selection of the appropriate procedures, strategies and techniques. Molina \& Albir (2002) has devised eighteen translation techniques. They are adaptation, amplification, borrowing, calque, compensation, description, discursive creation, established equivalent, generalization, linguistic amplification, linguistic compression, literal, modulation, particularization, reduction, substitution, transposition, variation. The techniques used by translators/subtitlers determine the quality of translation. $A$ translation product which has a high quality needs certain standards and criteria (Akhiroh, 2013). According to Nababan (1999), there are three criteria of translation quality assessment, namely accuracy, acceptability, and readability.

Fitria (2015) classified and described the translation technique and the translation quality of English to Indonesian subtitle of Doraemon "Stand By Me" movie. Based on the analysis, there are 11 types of translation techniques, such as adaptation, amplification, borrowing, calque, compensation, discursive creation, established equivalence, literal translation, modulation, reduction, and transposition. The most dominant type of translation technique is established equivalence. The result shows that the translation quality of "Stand By Me" Doraemon movie has high levels in terms of accuracy, acceptability and readability.

The research from Sari et al., (2016) aimed to describe the translation techniques, the translation quality, and the impact of translation techniques toward the quality of taboo words translations in VCD and amateur subtitles of The Wolf of Wall Street movie. The results of 
analysis showed that word and phrase were kinds of grammatical unit of taboo words. The dominant categories were sexual references and offensive slang. In VCD version, there were 6 translation techniques. They are established equivalence, reduction, amplification, literal translation, borrowing and generalization. Established equivalence contributed positively to the accuracy and acceptability. In addition, reduction created low level of accuracy, but it had acceptable translation. Meanwhile, 7 translation techniques applied in the amateur version such as established equivalence, reduction, amplification, borrowing, generalization, literal translation, and compensation. Established equivalence created high level in terms of accuracy and acceptability. Reduction and the other techniques affected low level of accuracy, but it created high level of acceptability.

From the previous researchers, this research concern to compare the translation technique and translation quality in Indonesian subtitles of Coco movie. Thus, the research aimed to (1) identify the translation technique used by Pein Akatsuki and Deni Aurora in Indonesian subtitles of Coco movie, (2) evaluate the translation quality used by Pein Akatsuki and Deni Aurora in Indonesian subtitles of Coco movie, and (3) find out the effect of translation techniques on the translation quality used by Pein Akatsuki and Deni Aurora in Indonesian subtitles of Coco movie.

\section{Method}

The research method used is descriptive qualitative. Descriptive qualitative is a research used to describe a natural phenomenon. This research is based on the work of translation. Descriptive qualitative research uses a qualitative data in the form of sentences.

The source data of this research are documents and informants. Data about translation technique are obtained from documents, which are movie scripts of Coco movie and two versions of its translation in Indonesian. The Indonesian subtitles are translated by Pein Akatsuki and Deni Aurora in www.indoxxi.bz. Meanwhile, data about translation quality are obtained from informants. Informants consist of raters to determine the level of translation quality. The data used in this research consist of two categories. The first category is 417 utterances of Miguel as the main character in Coco movie, and two versions of its translation in Indonesian. The second category is the results of questionnaires from the raters on the translation quality, including aspects of the accuracy, acceptability, and readability on its two versions of Indonesian subtitle in Coco movie.

Technique of data collection used is documents and questionnaires analysis. There are three kind of questionnaires used in this research which are the questionnaires to measure the accuracy, the acceptability, and the readability. After collecting the data, the data is analyzed descriptively by using technique used by Miles et al., (2014). There are three steps of data analysis, namely 1) data condensation, 2) data display and 3) conclusion drawing and verification.

\section{Results}

\section{Translation Techniques}

Pein Akatsuki applies 16 translation techniques in translating Indonesian subtitle of Coco movie such as literal translation, borrowing, modulation, linguistic compression, established 
equivalent, reduction, linguistic amplification, transposition, amplification, variation, compensation, calque, discursive creation, substitution, particularization, and adaptation.

Table 1. Translation Techniques Used by Pein Akatsuki in Indonesian Subtitle of Coco Movie

\begin{tabular}{llll}
\hline No. & Translation Techniques & $\mathrm{F}$ & $\%$ \\
\hline 1 & Literal translation & 170 & $24.67 \%$ \\
2 & Borrowing & 165 & $23.95 \%$ \\
3 & Modulation & 96 & $13.93 \%$ \\
4 & Linguistic compression & 82 & $11.90 \%$ \\
5 & Established equivalent & 39 & $5.66 \%$ \\
6 & Reduction & 29 & $4.21 \%$ \\
7 & Linguistic amplification & 21 & $3.05 \%$ \\
8 & Transposition & 17 & $2.47 \%$ \\
9 & Amplification & 16 & $2.32 \%$ \\
10 & Variation & 15 & $2.18 \%$ \\
11 & Compensation & 13 & $1.89 \%$ \\
12 & Calque & 10 & $1.45 \%$ \\
13 & Discursive creation & 8 & $1.16 \%$ \\
14 & Substitution & 3 & $0.44 \%$ \\
15 & Adaptation & 2 & $0.29 \%$ \\
16 & Particularization & 3 & $0.44 \%$ \\
\hline Total & & 689 & $100 \%$ \\
\hline
\end{tabular}

The number of translation techniques is more than the number of data because there are several data that need to be translated using more than one technique. Thus, the translation techniques are grouped into single (using one translation technique), couplet (using two translation techniques), triplet (using three translation techniques), and quadruplet (using four translation techniques).

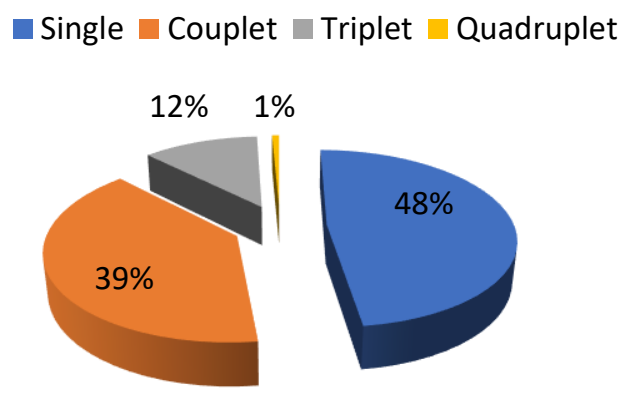

Chart 1. The group of Translation Techniques

The number of translation techniques used in the single group is 200 data. In the couplet, the translation techniques used are 165 data. In the triplet, the translation techniques used to translate 49 data. In the quadruplet, the translation techniques used to translate 3 data. 
Table 2. Translation Techniques Used by Deni Aurora in Indonesian Subtitle of Coco Movie

\begin{tabular}{llll}
\hline No. & Translation Techniques & $\mathrm{F}$ & $\%$ \\
\hline 1 & Literal translation & 228 & $34.49 \%$ \\
2 & Borrowing & 166 & $25.11 \%$ \\
3 & Modulation & 58 & $8.78 \%$ \\
4 & Linguistic compression & 43 & $6.51 \%$ \\
5 & Established equivalent & 40 & $6.05 \%$ \\
6 & Linguistic amplification & 33 & $4.99 \%$ \\
7 & Reduction & 23 & $3.48 \%$ \\
8 & Amplification & 22 & $3.33 \%$ \\
9 & Transposition & 14 & $2.12 \%$ \\
10 & Discursive creation & 10 & $1.51 \%$ \\
11 & Calque & 7 & $1.06 \%$ \\
12 & Particularization & 7 & $1.06 \%$ \\
13 & Compensation & 4 & $0.61 \%$ \\
14 & Variation & 3 & $0.45 \%$ \\
15 & Substitution & 2 & $0.30 \%$ \\
16 & Generalization & 1 & $0.15 \%$ \\
\hline Total & & 661 & $100 \%$ \\
\hline
\end{tabular}

Deni Aurora applies 16 translation techniques in translating Indonesian subtitle of Coco movie such as literal translation, borrowing, modulation, linguistic compression, established equivalent, linguistic amplification, reduction, amplification, transposition, discursive creation, calque, particularization, compensation, variation, substitution, and generalization. The number of translation techniques is also grouped into single, couplet, triplet and quadruplet.

Single $\square$ Couplet $\square$ Triplet $\square$ Quadruplet

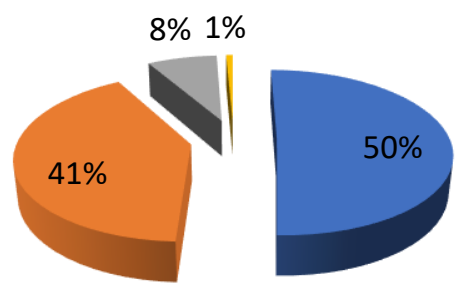

Chart 2. The group of Translation Techniques

The number of translation techniques used in the single group is 211 data. In the couplet, the translation techniques used are 171 data. In the triplet, the translation techniques used to translate 32 data. In the quadruplet, the translation techniques used to translate 3 data.

\section{Translation Quality}

The accuracy level of Indonesian subtitle by Pein Akatsuki shows that 244 data of accurate translation, 165 data of less accurate and 8 data of inaccurate translation. The acceptability level of translation quality of Indonesian subtitle by Pein Akatsuki identifies that there are 232 
data of acceptable translation and 167 data of less acceptable translation and 18 data of unacceptable. The readability level of translation quality Indonesian subtitle by Pein Akatsuki identifies that there are 349 data of high readability translation and 68 data of medium readability translation.

Table 3. Translation Quality of Indonesian Subtitle of Coco Movie by Pein Akatsuki

\begin{tabular}{llll}
\hline \multirow{2}{*}{ No. } & \multirow{2}{*}{ Translation Quality } & \multicolumn{2}{l}{ Pein Akatsuki } \\
\cline { 3 - 4 } & & F & $\%$ \\
\hline 1 & Accuracy & 244 & $58 \%$ \\
2 & Acceptability & 232 & $56 \%$ \\
3 & Readability & 349 & $84 \%$ \\
\hline
\end{tabular}

The accuracy level of Indonesian subtitle by Deni Aurora shows that 210 data of accurate translation, 196 data of less accurate and 11 data of inaccurate translation. The acceptability level of translation quality Indonesian subtitle by Deni Aurora shows that there are 205 data of acceptable translation, 191 data of less acceptable and 21 data of unacceptable translation. The readability level of translation quality Indonesian subtitle by Deni Aurora shows that there are 276 data of high readability translation, 138 data of medium readability translation and 3 data of low readability translation.

Table 4. Translation Quality of Indonesian Subtitle of Coco Movie by Deni Aurora

\begin{tabular}{llll}
\hline \multirow{2}{*}{ No. } & Translation Quality & \multicolumn{2}{l}{ Deni Aurora } \\
\cline { 3 - 4 } & & $\mathbf{F}$ & $\%$ \\
\hline 1 & Accuracy & 210 & $50 \%$ \\
2 & Acceptability & 205 & $49 \%$ \\
3 & Readability & 276 & $66 \%$ \\
\hline
\end{tabular}

\section{Discussion}

Based on the percentage of recapitulation in translation technique, Pein Akatsuki uses single technique consisted (48\%), couplet (39\%), triplet (12\%) and quadruplet $(1 \%)$ while Deni Aurora uses the single technique (50\%), couplet (41\%), triplet (8\%) and quadruplet (1\%). It is clear that subtitlers translate the subtitle use single and couplet technique more than triplet and quadruplet technique. They use some same techniques and have two different techniques such as adaptation used in the translation of Pein Akatsuki and generalization used in Deni Aurora's. Based on the frequency of translation techniques used, they show the same dominant techniques that are literal translation, borrowing, and modulation. The literal translation used to translate word by word literally. It meant that the text could be translated focused on the form and structure, without any addition or reduction. It emphasized the conformity to the translation language grammar of the TL.

The second most dominant technique used by both subtitlers is borrowing. It is applied to take word or expression directly from the source language to the target language. Modulation technique, the third, applied to change the point of view, focus or cognitive categories in relation to the source text. It can be lexical or structural. The subtitlers used this technique since the sentence structure of $S L$ and $T L$ is different or when the text is grammatically correct but awkward/unsuitable/not idiomatic in the TL. 
The fourth most used technique is linguistic compression, which applied by the subtitlers in a simultaneous translation of the translation or subtitles, by way of synthesizing linguistic elements in the target language but it does not change the meaning significantly. The fifth most applied technique belongs to established equivalent. Established equivalent is a technique that uses a terminology or expression recognized by dictionaries or language in use as an equivalent in the target language.

Reduction is placed in the sixth position by Pein Akatsuki and the seventh position by Deni Aurora. It is applied to suppress the information from SL into TL. Pein Akatsuki applies linguistic amplification and places the technique in the seventh position while Deni Aurora places it to the sixth, in which linguistic amplification is used to add linguistic elements in the target language.

Pein Akatsuki places transposition technique in the eighth position while Deni Aurora places the technique in the ninth. Transposition is a technique to change the grammatical categories of the source language into the target language. This technique replaces one word class with another but it does not change the meaning of the message. Amplification technique is placed in the ninth position by Pein Akatsuki and the eighth position by Deni Aurora. This technique used to add details of information in the TL without distorting the meaning of it.

Pein Akatsuki places variation in the tenth position while Deni Aurora places the technique in the fourteenth. Variation applied to change the linguistic or paralinguistic elements affect the aspect of linguistic variation. Compensation is placed in the eleventh by Pein Akatsuki and the thirteenth by Deni Aurora. It is used to replace the item information or position affects in the $S L$ in another place in the TL because it cannot be reflected in the same place in the SL.

Calque is placed in the twelfth position by Pein Akatsuki and the eleventh by Deni Aurora. The technique used by the subtitlers to translate the source language phrase literally, both lexical and structural. The thirteenth position and the tenth belong to discursive creation. Discursive creation applied to display an unexpected temporary match or out of context. The last positions belong to substitution, particularization, generalization, and adaptation. Substitution is a technique used to change the linguistic elements into paralinguistic elements (intonation or gesture). Particularization is a technique that uses more precise or concrete and specific term. Generalization is a technique that uses a more general or neutral term. Adaptation is used to replace the cultural elements of the source language with the cultural elements of target language.

Based on the percentage of recapitulation in translation quality, both subtitlers produce highquality translations. If it is compared, the accuracy of the translation of Pein Akatsuki is higher $(58 \%)$ than Deni Aurora's (50\%). It can be concluded that Pein Akatsuki can produce the equivalence translation with the message contained in the source language.

Next, based on the acceptability of translation, the translation of Pein Akatsuki is still higher by $56 \%$. Meanwhile, Deni Aurora's has $49 \%$ of acceptability. Thus, it can be implied that their translation frequently produces acceptable translation. Nevertheless, the translations of both subtitlers are still having a little problem with the use of grammatical or words choice in the target language which are unfamiliar to the audience and it will make the translations are less acceptable.

Then, based on the readability of translation, Pein Akatsuki has a high level of readability higher than Deni Aurora's. It can be seen that Pein Akatsuki has $84 \%$ while Deni Aurora has 
$66 \%$ of high readability. However, the translation of Pein Akatsuki is easier to understand than Deni Aurora's.

For both subtitlers, literal translation and borrowing contribute positively to the effect on the translation quality that cover the high level of accurate, acceptable, and readability. The alteration in word orders are adjusted to the word order in the target language through applying literal translation technique. If not, the translation will probably go against the applied rule in the target language or Indonesian. Such translation commonly led to distortion in meaning and difficulties for the readers to comprehend the texts. Pein Akatsuki employs established equivalent, transposition, amplification, and adaptation which also include in accurate, acceptable, and high readability. Linguistic amplification, particularization, and compensation are categorized into high level of accurate and readability but less acceptable. The modulation, linguistic compression, reduction, variation, calque, and substitution appear to less accurate and less acceptable, but it has high readability. Discursive creation is classified into less accurate, less acceptable, and medium readability. Meanwhile, Deni Aurora applies linguistic compression, established equivalent, and generalization in high level of accurate, acceptable, and readability. Variation is included in accurate, acceptable but medium readability. Substitution belongs to accurate and high readability but less acceptable. Transposition and particularization are classified into acceptable translation but less accurate, and medium readability. Modulation, reduction, linguistic amplification, amplification, compensation, calque, discursive creation is categorized into less accurate, less acceptable, and medium readability.

\section{Conclusion}

Based on the result performed in this research, Pein Akatsuki and Deni Aurora employ 16 translation techniques. Literal translation as both subtitlers' most frequently used technique. The analysis of the translation quality shows that the translation of Pein Akatsuki applies in high level of accurate, acceptable, and readability than Deni Aurora does in terms of accuracy, acceptability, and readability. For both subtitlers, literal translation and borrowing contribute positively to the effect on the translation quality that covered the high level of accurate, acceptable, and readability. The other techniques of modulation, linguistic compression, established equivalent, reduction, linguistic amplification, transposition, amplification, variation, compensation, calque, discursive creation, substitution, adaptation, particularization, and generalization also can produce the accuracy, acceptability, and readability of translation while there is a small part of the applying which is less precise so it produces the translation which appears to less accurate, less acceptable and medium readability.

This research finding in relation to the choice of translation technique affects the translation quality in terms of accuracy, acceptability, and readability. This research just focuses on one aspect of translation which is the subtitle (AVT) as the translation product. Therefore, it is suggested for future researchers to conduct research on different aspects of translation in AVT such as examining the comparative study about translation strategies, methods, and ideologies occurred in different translator.

\section{Acknowledgment}

$\mathrm{N} / \mathrm{A}$ 


\section{References}

Akhiroh, N. K. (2013). The influence of translation technique on the quality of the translation of international news. Language Circle Journal of Language and Literature, 7(2). https://journal.unnes.ac.id/nju/index.php/LC/article/view/2597

Aveline, R. G. Z. (2015). Subtitling Strategies and Translation Readability of the Indonesia Subtitle of Maleficent Movie. In undergraduate thesis. Semarang State University.

Chang, Y. (2012). A tentative analysis of English film translation characteristics and principles. Theory and Practice in Language Studies, 2(1). https://doi.org/10.4304/tpls.2.1.71-76

Fitria, T. N. (2015). Translation Technique of English to Indonesian Subtitle in Doraemon "Stand by Me" Movie. SSRN Electronic Journal. https://doi.org/10.2139/ssrn.3527873

Kinasih, A. K. (2016). An Analysis on The Translation Strategies Employed in The English Subtitles of Thai's Music Videos and Their Semantic Errors. Seminar Tahunan Linguistik 2016, 6-11.

Miles, M. B., Huberman, M. A., \& Saldana, J. (2014). Qualitative Data Analysis. Sage Publications, Inc.

Molina, L., \& Albir, A. H. (2002). Translation techniques revisited: A dynamic and functionalist approach. Meta: Journal Des Traducteurs, 47(4). https://doi.org/10.7202/008033ar

Nababan, M. R. (1999). Teori Menerjemah Bahasa Inggris [Theory of Translating English]. Pustaka Pelajar.

Sari, N. I., Nababan, M. R., \& Djatmika, D. (2016). Analisis Perbandingan Teknik Penerjemahan Istilah Tabu Dalam Film The Wolf of Wall Street dan Dua Terjemahannya (Subtitle Resmi VCD dan Amatir Dari Situs Subscene.Com) Serta Dampaknya Pada Kualitas Terjemahan. PRASASTI: Journal of Linguistics, 1(1). https://doi.org/10.20961/prasasti.v1i1.910 